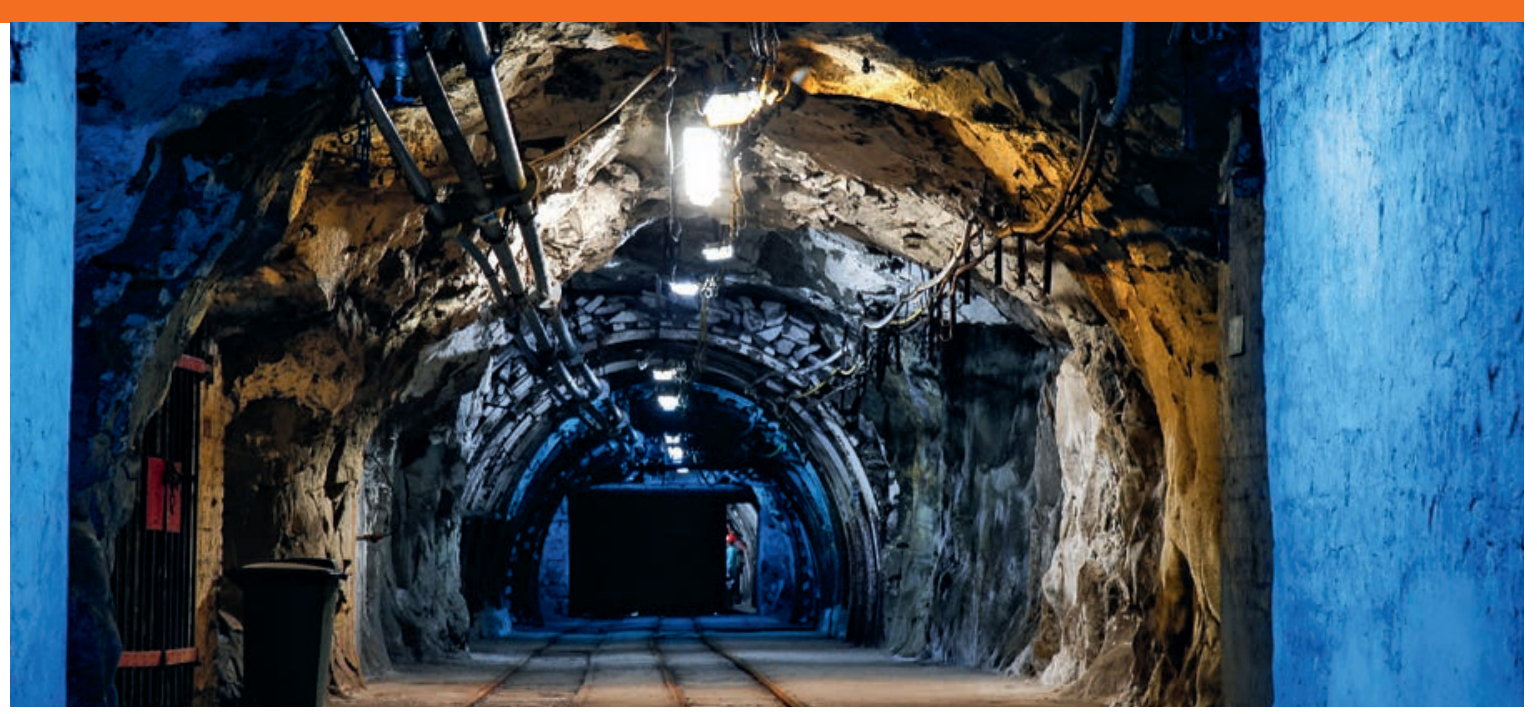

\title{
Im Untergrund
}

\section{Erhard Taverna}

Dr. med., Mitglied der Redaktion

Bildnachweis

(c) Aniuszka |Dreamstime.com

Literatur

Horizonte-Das Schweizer Forschungsmagazin Nr. 118, September 2018 Jules Verne, Reise zum Mittelpunkt der Erde, Kindle Edition.
Vom zehnten Stock der Chirurgie geht der Blick hinab zu Baggern und Lastwagen. Hohe Bauten brauchen massive Verankerungen, und für das neue Spital geht es noch einmal sieben Stockwerke in die Tiefe. Laut Horizonte Nr. 118 wird es untertags langsam eng. Geothermie und Cargo sous terrain könnten mit Tunnel, Erdöllagern und Enddeponien für radioaktive Abfälle in die Quere geraten. Nicht zu reden vom Kabelnetz, Abwasserstollen und Bunkeranlagen. Wem dieser öffentliche oder private Untergrund letztlich gehört, ist unklar geregelt. Das ZGB begrenzt das Grundeigentum nach unten und oben gemäss den Interessen der Eigentümer. Nach römischem Recht umfasst das Grundeigentum den ganzen Bereich bis zum Erdzentrum. Eine schöne Vorstellung. Man rechne die Mantelfläche eines Zylinders mit einer Höhe von rund $6300 \mathrm{~km}$, zusätzlich geschenkt zu den Quadratmetern einer kreisförmigen Parzelle. Wer will da noch über hohe Bodenpreise meckern?

Der rüstige Endsiebziger L. war jährlich für einen Checkup in der Sprechstunde. Als fitter Reiseleiter jeden Frühling mit einer Wandergruppe auf Elba und Lipari unterwegs, im Herbst schon lange vor der Jagd mit einem Feldstecher über Berg und Tal. L. hatte immer etwas zu erzählen, und man war gut beraten, ihn für eine Randstunde einzuschreiben. Die damalige Bundesrepublik finanzierte eine grosszügige Rente und einen jährlichen Kuraufenthalt im Schwarzwald. Letzteren verdankte er einem Unfall im Bergstollen, in einem der zahlreichen Zechen des Kohlepotts, wie er stolz sein Arbeitsgebiet nannte. Als jahrzehntelanger Bergmann in den Schächten des Ruhrgebiets hatte er mehr Tage unter der Erde als über ihr verbracht. Abgesehen vom den längst verheilten Knochenbrüchen hatte das vielleicht auch mentale Folgen. Denn L. war ein Anhänger der Hohlwelttheorie, die darauf beruht, dass wir auf der Innenfläche einer Weltkugel leben mit einem Fixstern im Zentrum, um den Mond und Sonne kreisen. Eine etwas komplizierte Vorstellung, auf die er aber sehr stolz war. Was Geologen und Astronomen behaupten, brachte ihn nicht aus der Ruhe. Schliesslich war er der Experte und stützte sich auf eigene Beobachtungen. Jules Vernes Klassiker Reise zum Mittelpunkt der Erde hatte er natürlich auch gelesen. Amüsant befand er, gut geflunkert wie alle Karl-MayGeschichten, deren Bände er vollzählig im Buchregal besass. Professor Lidenbrock steigt bei Verne mit seinen Begleitern durch einen erloschenen isländischen Vulkan und kommt nach vielen Abenteuern aus dem Krater des Stromboli wieder an die Oberfläche. L. wusste es besser, bestieg er doch jedes Jahr den rauchenden Berg.

Jahrelang wurde auf der Halbinsel Koala zu wissenschaftlichen Zwecken in die Tiefe gebohrt. Eine Briefmarke aus sowjetischen Zeiten zeigt den haushohen Bohrturm. Gut zwölf Kilometer reichte die Sonde in die Tiefe. Zu wenig um die Schale der Hohlwelt nach aussen zu durchbrechen, zu viel um nicht auf Jules Vernes Urmeer und lebendige Saurierwelt zu stossen. Unerklärliche Geräusche sorgten jahrelang für Gerüchte, die über das US-Fernsehen verbreitet wurden. Es klang wie vielstimmige Schreie, als hätten die Ingenieure Dantes Inferno angebohrt.

Vorläufig wird nur kartiert und gemessen. Bis das Projekt Geomol 17 realisiert ist, das alle grossen Städte des Mittellandes mit einem Warentunnel verbinden will, ist noch mit vielen weiteren Nebengeräuschen zu rechnen. Nicht nur aus dem Reich der Toten. 